\title{
Analyzing the Skeleton-spatial Development in Yazd and Measuring Its Conformity with the Smart Growth Pattern
}

\author{
Forough Ghasemi
}

Master of Science in Geography and Urban Planning, Marvdasht, Iran

Leila Jalalabadi

PhD, Student in Department of Geography and Urban Planning, Payam-Noor University, Po Box 19395-3697 Tehran, I.R of Iran Email: Leyla_jalalabadi@yahoo.com

Morteza Yavari

Department of Urban Design, Faculty of Art and Architecture, University of Zabol, Iran

\section{Leili Ovieisi}

MA in Geography and Urban Planning, Islamic Azad University, Zahedan

Doi:10.5901/mjss.2015.v6n4s2p555

\section{Abstract}

This article aims at and analyzing the skeleton -spatial pattern in Yazd and measuring its conformity with the smart urban growth pattern. This research is the applied type and its method is descriptive and analytic. Data gathering method has been of two methods, library and field study. To measure the skeleton farm and recognize the skeleton development pattern of the city, Garry coefficient, Mara, coefficient, Shannon Entropy model and intender model have been used. To measure the conformity of Yazd Skeleton growth pattern by using Constant development indicators, experts were asked to do same surveys and questionnaires results of questionnaire are analyzed by using spss software .results of the research and calculating Moran and Gary coefficient, indicates that according to the degree of gathering and dispersion of population and activity ,Yazd follows a random to sprawl pattern. Copulating Shannon Entropy also confirms the urban sprawl growth in Yazd. According to the results of Heldern model 60 percent of Yazd growth during 1981 to 2011, is related to population growth and 40 percent is based on city's spiral and horizontal growth that has led to the reduction in population compression and increase in shared urban land at last expansion in Yazd horizontal spiral form . Measure the growth pattern conformity and development of Yazd with the indicators of smart urban growth pattern indicates its lock of conformity, The final result would be that during the past few decades, growth and development pattern in Yazd been desirable and is not conforming to Smart Urban development.

Keywords: Physical Development, Growth Aspral, Smart Growth, Heldern Model, YazdCity

\section{Introduction}

Urban development on its developing course has been quite balanced since its beginning till now, as in most urban sites, All Urban elements have been of an extraordinary coincidence and superposition (1).

Social -Cultural and economical transitions of 19th and 20th century derived from modernism , has led to fast city developments and creation of big cities and city-regions and have caused basic changer in structure and their skeletonspatial form (2) paying attention to constant urban physical development as a main necessity in urban development plans indicates the importance of this matter in reinforcing Social, Cultural and skeleton form of city (3). And has made all the officials, managers and experts a solution (4).

Urban physical development means expansion and extension of city's Skeleton spaces (5). If the physical development is organized, rhythmical and balanced, it will be desirable .but if physical development in different parts of city is non rhythmical and disorganized, it causes urban (6). They have tried hard to remove the negative effects of dispersed distribution of cities and the most prominent of their attempts is the procedure of smart growth as one of the 
possible ways against "sprawl" in urban development that in fact ,smart growth is Considered to be an alternative for sprawl (7).

Smart growth is a planning ( urban and regional ) and transportation theory that focuses on preventing dispersed distribution of city so that, it will focuses on downtown growth (8) and it Supports the compact Usability toward public transportation which can be used by pedestrians and bicycle riders that includes development with mixed usability and different sorts of house choices.

This theory also takes into account the long and regional considerations and short term constancy theory (9).

Smart growth is of development alternatives against sprawl. Smart growth aims at building public places by focusing on renewing urban life and developing transportation Choices, so that people will like living there (2).

Yazd which has originated from a besieged castle (10)has been experiencing a quiet growth, In this land procedure, traditional efficiency was considered to be sufficient and had been settling the city space according to economical ,Social and security conditions .But after this permanent and new Currency in models and ways of land use ,and because of the lack of a design and an experienced manager ,Land has grown Surprisingly and has formed different types of skeleton organs . progress in this condition ,not only has broken off city's solidarity but it has also increased economical, social difficulties (11).Based on all these facts the main purpose of this research is measuring and analyzing physical form of Yazd city and Studying its conformity with model of optimized urban development. So research questions are as follow:

How is Yazd Spatial -skeleton development Model?

Do the skeletal model-space city of Yazd consistent with smart urban growth model?

\section{Research Background}

Different research has been done with expansion of skeletal-space and measurement of cities revises the growth model with smart urban. Rahnama and Abbaszadegan in research (2006) study comparative degree Transmittal/crushing in metropolitans Sydney and Mashhad depravities. This research by using GIS tools and by introducing four model (Entropy, Jinee ,Moran and Geary) indices for compression metropolitans Sydney and Australia and Mashhad in Iran is calculated in such a way that in the city Sydney model focused almost random pattern and Mashhad has been calculated. Gharakhlo and Zanganeh research (2009) recognized as a skeleton-spatial growth pattern city by using the models become more indecent a little (Entropy, Jinee ,Moran and Geary) in Tehran city, recognition and measurement model skeletal growth-space Tehran in different periods, the degree distribution of balanced density and postwar period as used and the numbers suggest inequality and lack of balance in the distribution of population in the city and city physical model of development Tehran gathering and the concentration on the model have low dispersion model city and somewhat random closer. Mohammad Hussein Saraee (2005) with research under the title "supply process and its influence on the expansion of cities quality; the city of Yazd (The author in the treatise that the search for causes of horizontal expansion of city of Yazd and paid in this regard to the factors like possession and the handing over of the land by the government absorbing the earth city limits in the plan of the city and the project of preparing the earth has pointed out.

\section{Method and Material}

Research method: This research is the applicable type and its method is descriptive and analytical. way of gathering needed date for this is descriptive and analytical .way of gathering needed data for this research is of two types: library and field .in Library way .articles ,books research proposals , thesis ,maps and achieved information of some offices and organizations have been used .In field way needed information is gathered through observation and experts, questionnaire To measure the Skeleton form , and recognize the city skeleton development model Moran and Gary coefficients and Entropy modal and Heldern moderl are used .To measure the Conformity of Yazd growth model with constant development indicators, questionnaire and surveys from experts were used. And the results o the questionnaire have been anodized by using spss statistical Software.

\section{Introducing the Under Studying Boundary}

Yazd is the second historical "raw brick "City of the world which is one of the cities in Iran and is the center of Yazd province and is located on Es Esfahan-Kerman route. This city is placed between 54 degrees and 18 minutes to 54 degrees and 24 minutes of Eastern longitude and 31 degrees and 40 minutes to 31 degrees and 56 minutes of northern latitude and contains an area of about $91 \mathrm{~km}^{2}$.its average altitude in Amir Chakhmagh ( city center) is 1218 ( Iran 
topography organization ,2011).

\section{Results and Discussion}

To determine the degree of gathering and dispersion of city, spatial self correlation processes are used that you can evaluate the level and degree of gathering and dispersion in the city by measuring the self-correlation and for this reason Moran and Gary coefficients ore used. Spatial self-correlation is that correlation between the same variables in Moran different places:

(12)Moran coefficient is defined as fallowing: (13)

$\mathrm{I}=I=\frac{n \sum \sum w i j\left(x_{i}-x^{-}\right)\left(X j-x^{-}\right)}{\sum \sum w_{i j} \sum(x-c)^{2}}$

$\mathrm{n}$, is the number of small regions .xi is the population or the employment in small region of $\mathrm{I}$, xi is the population or employment in small region of $j, x$ is the variable of population or employment and wij identifies the weight between two regions of $I$ and $j$. Moran coefficient is arranged from -1 to +1 it Its high value indicates much gathering with high compression and the value which is close to zero ,means a random gathering and -1 indicates a checkered model of development.

Geary's coefficient is also similar to Moran coefficient but instead of focusing on mean deviation, it evaluates the difference of each region against another one and formulates it as below:

Geary $=\operatorname{Geary} \frac{(n-1) \sum \sum w i j(x i-x j)^{2}}{2 \sum \sum w i j \sum(x i-x)^{2}}$

Geary's coefficient is arranged between 0 to 20 .In order to having a measurement similar to Moran's, it can charge like the $3 \mathrm{rd}$

Adjusted Geary= - (Geary-1)

Adjusted Geary's coefficient like Moran's is from -1 to +1 that its high valve indicates much gathering with high compression and the valve which is close to zero, it means random gathering and the value of- 1 indicates checkered model (14) The results of calculating moron's and Geary's Coefficient for Yazd city are shown in table 12 .Moran's coefficients which were calculated the employment and population indicate a random model and the case that this model mostly tends toward growl than cluster model. Geary's Adjusted coefficient for population and employment in Yazd city was calculated by zero and one way which both are reality close to random model and tends toward sprawl that conforms to the results of Moran s coefficient .According to the Calculations done in Yazd City it follows the random model toward sprawl considering the degree of gathering and population and activity sprawl.

Table (1). Gary and Moran coefficients for Yazd

\begin{tabular}{ccccll}
\hline Amount 2011 & Amount1385 & Amount1380 & Amount1375 & Parameter & Different Coefficients \\
\hline-0.158 & -0.211 & -0.180 & -0.179 & population & \multirow{2}{*}{ Moran (Mode 0 and 1) } \\
-0.154 & -0.210 & -0.183 & - & Employment & \\
-0.056 & -0.175 & 0.133 & 0.105 & population & Moran (Method common border) \\
-0.048 & -0.135 & 0.159 & - & Employment & \\
1.040 & 1.083 & 1.139 & 1.143 & population & Geary (method 0,1) \\
1.021 & 1.096 & 1.141 & - & Employment & \\
-0.040 & -0.083 & -0.139 & -0.143 & population & Modulator Geary (method 0,1) \\
-0.021 & -0.096 & -0.141 & - & Employment & \\
\hline
\end{tabular}

Source: writer's accounting

Measuring sprawl growth of City is difficult and ambiguous (15) But considering it there are a number of measurement and parameter which are used to measure urban sprawl growth. One of these models is Entropy's model .In fact this model is going to be used to analyze and determine the amount of urban deform growth phenomenon (16). The value of Entropy is from zero till Ln (n). Zero value indicates the City's so compressed physical development, while the Ln (n) valve indicates the urban sprawl physical development .when the Entropy's value exceeds $\operatorname{Ln}(\mathrm{n})$,we can ,claim than urban sprawl growth has happened.(17)

$$
\mathrm{H}=-\sum_{i=j}^{n} p
$$

Here, in 2011 Entropy for the area of q regions Yazd city was calculated and 2.133 was gained when $\operatorname{Ln}(\mathrm{n})$ is equal to 2.147 Closeness to Entropy valve to the maximum, indicates sprawl growth of physical development .So Yazd 
city is of sprawl physical development.

Table (2). Shannon Entropy calculated 2006 in Yazd

\begin{tabular}{ccccc}
\hline $\mathbf{P}_{\mathrm{i}}{ }^{*} \mathbf{L n} \mathbf{P}_{\mathrm{i}}$ & $\operatorname{Ln} \mathbf{P}_{\mathrm{i}}$ & $\mathbf{P}_{\mathrm{i}}$ & area & Urban areas \\
\hline-0.24 & -2.21 & 0.11 & 1062 & $\mathbf{1 - 1}$ \\
-0.23 & -2.29 & 0.10 & 977 & $\mathbf{2 - 1}$ \\
-0.18 & -2.71 & 0.07 & 640.3 & $\mathbf{1 - 2}$ \\
-0.23 & -2.32 & 0.10 & 947 & $\mathbf{2 - 2}$ \\
-0.21 & -2.42 & 0.09 & 861 & $\mathbf{3 - 2}$ \\
-0.24 & -2.26 & 0.10 & 1011.2 & $\mathbf{4 - 2}$ \\
-0.27 & -2.02 & 0.13 & 1284.4 & $\mathbf{1 - 3}$ \\
-0.33 & -1.51 & 0.22 & 2129 & $\mathbf{2 - 3}$ \\
-0.20 & -2.56 & 0.08 & 748 & historical \\
-2.133 & \multicolumn{5}{c}{ Total } \\
2.133 & \multicolumn{5}{c}{ Shannon Entropy1390 } \\
\hline
\end{tabular}

Another main methods of identifying urban sprawl growth is the use of Heldern model .By using this model .You can identify how much of the city's growth is resulted from population growth and how much is resulted from urban sprawl growth (18). This model was first applied by Heldern in 1991 to calculate the ratio of population to every other Source (19).This model Levels are as follow(16) .

(1) $=\mathrm{a}=\frac{A}{p}$

In (1) gross share (a) equals to division of land area (A) to population $(P)$.it can be concluded that a whole land that is occupied by an urban region (A) equal to product of grass .share (a) and population .So we will have:

(2) : $A=p x a$

According to Heldern method, if population increases by $(\Delta p)$ during the period of $(\Delta t)$, and the land use share Changes by $(\Delta p)$ all the urban Lends will increase by $(\Delta p)$.and then by replacing in 2 correlation You will Conclude:

(3) : $\mathrm{A}+\Delta \mathrm{A}=(\mathrm{P}+\Delta \mathrm{p}) \cdot(\mathrm{a} . \Delta \mathrm{a})$

By replacing (2) and (3) relation and dividing it by $(A)$.You can have the changes in boundary area $(\triangle A / A)$ which has turned into a city .during the period of $(\Delta \mathrm{T})$ :

(4) : $\frac{\Delta \mathrm{A}}{A}=\frac{\Delta \mathrm{p}}{p}+\frac{\Delta \mathrm{a}}{a}+\left(\frac{\Delta \mathrm{p}}{p}\right) \cdot\left(\frac{\Delta \mathrm{a}}{a}\right)$

Considering this, By following Heldern model, (4) relation shows that the percentage of a city growth

$100)$ and precertage of grass unit growth $\left(\frac{\Delta A}{A} \times 100\right)$.

In other words 4 relation is:

(5):Total percentage of non net share growth $t$ total percentage of city's population growth = total percentage of towns extent (space)

Based on this fact the share of population growth of the Land Sum is gained by the Change ratio of the whole population in one era to the whole percentage change of Land Content of Same era can be stated as: the share of land (6)growth $=\frac{\text { tatal percentage of populatien }}{\text { urit of land conten }}$

For the land share you can similarly calculate the share for Land growth

(7) The share of Land growth $=\frac{\text { tatal percentage of land appliccabtity share growth }}{\text { tatal perceetage of lands contens growth }}$

According to population growth model, Heldren offers a general model to complete own model:

(8): $P t=p 0(1+g p) t$

In which, pt is the population in time (t), po is the initial population, $\mathrm{gp}$ is the population growth during a period .To solve gp you can use the following formula $(9): \ln (1+q p)=\left(\frac{1}{t}\right) \ln \left(\frac{p t}{p 0}\right)$

Because $\operatorname{In}(1+x)$ is almost $X$ for the values which are lower than $x$ You can write(9) equation as:

(10): $g_{p=\frac{1}{t}} \operatorname{In}\left(\frac{p t}{p_{0}}\right)$

The results of growth rate can also be written for land content (A) and share of Land usability

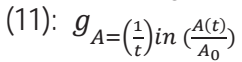


(12): $g_{a=\left(\frac{1}{t}\right) \operatorname{in}\left(\frac{a(t)}{a_{0}}\right.}$

So, .Based on these 3 growth rate Heldern equation can be written as:

(13): $q_{p}+q_{a}=q_{A}$

By making formula (10-12) for the degree of growth and relationship between initial values and ending period of variables $a, A$, p during the period in (14) equation, we have

(14): $\ln \left(\frac{q}{w}\right)+\ln \left(\frac{e}{r}\right)=\operatorname{Ln}\left(\frac{y}{s}\right)$

Which, in this formula, $r$ is the population at the end of determined period and $w$ is the population in the beginning of the period, $\mathrm{e}$ is the ending nonet share $\mathrm{q}$ is the beginning nannet share $\mathrm{y}$ is the city content at the end of the period and $\mathrm{s}$ is the city content for the beginning time. The same situation for Yazd is as follow:

Table 3. Components of Model Heldern

\begin{tabular}{lll}
\hline $\mathbf{2 0 6 3 8 4}$ & The start of population 1360 & $\mathbf{W}$ \\
\hline $\mathbf{4 8 6 1 5 2}$ & End of population1390 & $\mathbf{R}$ \\
\hline 125.978Sq.m. & Start of per capita gross & $\mathbf{Q}$ \\
\hline 208.453 Sq.m. & GDP per capita over the period & $\mathbf{E}$ \\
2600Hectare & The area of the town at the beginning of the period & $\mathbf{S}$ \\
10134Hectare & The area of the town at the end of the period & $\mathbf{Y}$ \\
\hline
\end{tabular}

Which by placing these numbers in 4 equations we conclude that:

$$
\begin{aligned}
& \text { (15): } \ln \frac{486162}{2 A 6] 84}+\operatorname{In}\left(\frac{208.463}{125.978}\right)=\ln \left(\frac{10134}{1600}\right. \\
& \text { (16): } 2 / 3555+1 / 6 / 546=3 / 8976 \\
& \text { (17): } 0 / 8567+/ 5035=1 / 3603 \\
& \text { (18): } \frac{0.8567}{/ 03603}+\frac{(0.6035)}{/ 03603}=\frac{103602}{103603}
\end{aligned}
$$

After this and by using 18 and 19 equations the shares related to the percentage of population growth and percentage of urban land gross share is gained by deriding each side of equation to 1.8648 :

(19) $0.6+0.4=1$

So, considering all the above equation we can conclude that 60 percent of city's growth during years1982 to 2011 is related to the growth to population and 40 percent left, is related to horizontal and spiral growth of the city that it reduction to horizontal and spiral growth of the city that it leads to the reduction in gross dispersion of population and increase of urban land gross share and finally the spiral and deform horizontal development of Yazd city.

The degree of conformity between Yazd features and urban smart growth and development features was measured after recognizing its growth model and skeleton development.10 features were considered to measure the optimized urban growth and development and compared to Yazd city which are shown in table4 these features are the standard ones which are taken into account by different experts for urban smart growth.

Table 4: 10 features of smart growth and optimized urban development:

\begin{tabular}{l}
\hline 1-desired spatial distribution of urban services \\
\hline 2-desired spatial distribution of city's population \\
\hline 3- desired spatial distribution of employment \\
\hline 4-Providing different and various ways of transportation \\
\hline 5. Desired access to all regions and quarters of the city with no traffic \\
\hline 6. Conserving outdoors and Farm lands. \\
\hline 7. Making streets and quarters which are suitable for pedestrians. \\
\hline 8. Creating on spectrum of choices and ways for inhabitants. \\
\hline 9. Design compact buildings and making compactness. \\
\hline 10. Usability of mixed Lands. \\
\hline
\end{tabular}


Table 5: Mean, standard deviation, Median, Mode, minimum, maximum, variance and ..... are shown for each of the 10 .

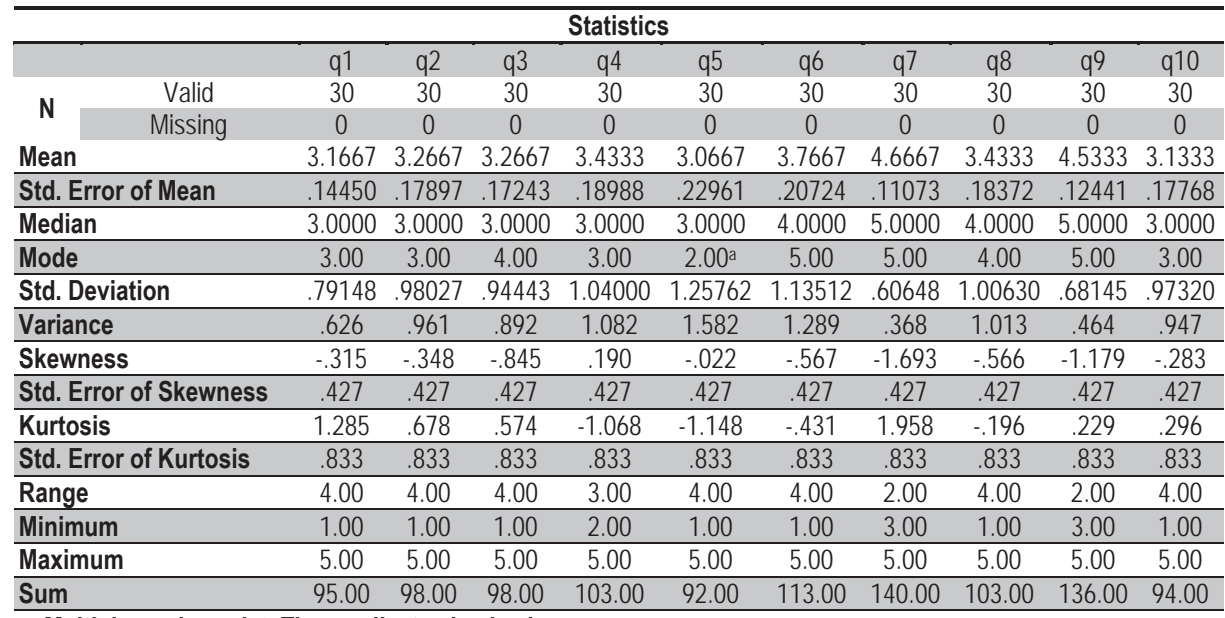

a. Multiple modes exist. The smallest value is shown

Source: writer's accounting

Table 6: meaning fullness of each compilations of theory is measured by using the one sample test .All the 10 compilations were found to be meaningful (valid)

\begin{tabular}{|c|c|c|c|c|c|c|}
\hline \multicolumn{7}{|c|}{ One-Sample Test } \\
\hline & \multicolumn{6}{|c|}{ Test Value $=2.5$} \\
\hline & & & & & \multicolumn{2}{|c|}{ 95\% Confidence Interval of the Difference } \\
\hline & $\mathrm{t}$ & df & Sig. (2-tailed) & Mean Difference & Lower & Upper \\
\hline q1 & 4.614 & 29 & .000 & .66667 & .3711 & .9622 \\
\hline$q 2$ & 4.284 & 29 & .000 & .76667 & .4006 & 1.1327 \\
\hline q3 & 4.446 & 29 & .000 & .76667 & .4140 & 1.1193 \\
\hline$q 4$ & 4.915 & 29 & .000 & .93333 & .5450 & 1.3217 \\
\hline q5 & 2.468 & 29 & .020 & .56667 & .0971 & 1.0363 \\
\hline q6 & 6.112 & 29 & .000 & 1.26667 & .8428 & 1.6905 \\
\hline$q 7$ & 19.568 & 29 & .000 & 2.16667 & 1.9402 & 2.3931 \\
\hline q8 & 5.080 & 29 & .000 & .93333 & .5576 & 1.3091 \\
\hline q9 & 16.343 & 29 & .000 & 2.03333 & 1.7789 & 2.2878 \\
\hline$q 10$ & 3.564 & 29 & .001 & .63333 & .2699 & .9967 \\
\hline
\end{tabular}

Source: writer's accounting

Total average of marks for responders to the total indicators is 15.8 that indicates that the indicators of smart urban growth of Yazd city are lower than average .one sample test confirmed the validity of all the compilations too. So the results show the Lack of conformity of Yazd features with principles and features of smart urban growth.

\section{Conclusion}

New development patterns city of Yazd in contrast with traditional patterns that has caused problems in the literature double urban development. On the other hand, the marginal rural tissue within city borders drawn model and caused historical development of physical tissue and on the other hand agricultural lands and gardens with this rural tissue into reclaims waste lands attached to the city current and development of model edges has. In the process formation of this growth patterns, urban projects by absorbing the earth repeatedly blame the major.

The results of statistical studies and analyzing Shannon models Moran coefficient, Geary's coefficient and Heldern 
Model indicate an spiral an deformed skeleton growth of Yazd city .According to the result, 60 percent of city growth during 1982 to 2011 was related to population growth and 40 percent left was related to horizontal and spiral growth of the city that results in the reduction of rennet gathering of population and increase in gross share of urban and at last increase in horizontal spiral and deformed development of Yazd measuring the conformity of Yazd skeleton development of Yazd Measuring the conformity of Yazd skeleton development model with indicators of smart of smart urban growth indicates the lock of conformity So, Yazd city requires exact planning to balance the future growth and development.

\section{References}

Hosseini,SH \& Solleymani Moghaddam , H. (2006) Urban development and undermine the concepts of neighborhood, housing and the Quarterly, №. 113.

Ziyari, K, (2009), the social - cultural and spatial development of the Industrial Revolution in Tehran, Journal of Geography and Development, №. 1.

Hosseinzadeh Dalir, k, \&, Hoshyar, H (2006),views, elements affecting the physical development of cities, Journal of geographical area, No. 6.

Pour-Mohammadi, M \& Jamali F \& Asghari Zamani,A (2008) Assessment of Open Space - spatial sampling with emphasis on land use change over the period 1384-1385, Journal of Geographical Research, No. 63.

Glaeser Edward, L. \& Matthew E. Kahn, (2004), Chapter 56 Sprawl and urban growth, Handbook of Regional and Urban Economics, Volume 4.

Pourahmad, A \& Shamaei,A (2001) the physical development of the city of Yazd and its impact on the historic fabric of the city, a Social Sciences, No. 18.

Ghorbani,R \& Nooshad, S. (2008), Smart Growth Strategy in Urban Development, Geography and Development, No. 12.

Gabriel Steven A., \& Glenn E. Moglen, (2006), A multiobjective optimization approach to smart growth in land development, SocioEconomic Planning Sciences, Volume 40, Issue 3.

Abbaszadgan, M. \& Rostami-Yazdi, B. (2008), the use of smart growth organization sparse growth of cities, Journal of Technology and Education, Third Year, Volume 3, NO. 1.

Fattahi, M (2000) Development of land for residential use planning: case study of Yazd, MA thesis, Geography and Urban Planning, Yazd University.

Saraee, M. H. (2009) Physical Development Yazd multiple models, Journal of Geographical Research, No. 84. .

Getis A, (2005), Spatial Pattern Analysis, Encyclopedia of Social Measurement, Volume 3.

Rahnama, M,\& Abbaszadeh,G (2006) comparative study to assess the degree of dispersion / compression in the Sydney metropolitan cities of Mashhad, Journal of Geography and Regional Development, No. Vl.

Underwood Jared G., J, Francis \& Leah R. Gerber, (2011), Incorporating biodiversity conservation and recreational wildlife values into smart growth land use planning, Landscape and Urban Planning, Volume.

Hasse John E. \& Richard G. Lathrop, (2003), Land resource impact indicators of urban sprawl , Applied Geography, Volume 23, Issues 2-3.

Bhatta B. \& S. Saraswati, D. Bandyopadhyay, (2010), Urban sprawl measurement from remote sensing data, Applied Geography, Volume 30, Issue 4.

Hekmatnia, H.\& Mousavi , M(2006), the use of models in geography, modern publications.

Gharakhlou, M, \& Zangene, S (2009) Understanding patterns of physical growth - urban space using small models (case study: Tehran), Journal of Geography and Environmental Planning, No. 23.

Sutton P. C., (2003), A scale-adjusted measure of "Urban sprawl" using nighttime satellite imagery, Remote Sensing of Environment, Volume 86, Issue 3. 100, Issues 1-2. 